\title{
Step Unit of Distance
}

National Cancer Institute

\section{Source}

National Cancer Institute. Step Unit of Distance. NCI Thesaurus. Code C111318.

A unit of measure to quantify the number of strides taken during a normal walking gait. 